\title{
A qualitative investigation of adolescent participation in Care Groups for improved maternal and child nutrition: experiences from rural Zimbabwe
}

\author{
Pamela Ncube-Murakwani \\ Nutrition and Health Specialist, International Medical Corps \\ pmurakwani@yahoo.co.uk
}

Acknowledgements: This study was facilitated through the USAID Food For Peace funded Amalima program in Zimbabwe. The author would like to recognise the invaluable input from the following reviewers:

Shiromi Perera; Technical Officer, International Medical Corps

David Brigham; Chief of Party (Amalima program), Cultivating New Frontiers in Agriculture

Dr Nqobile Ncube; Deputy Chief of Party (Amalima program), Organization of Rural Associations for Progress

Jennifer Majer, Monitoring, Evaluation and Accountability and Learning Adviser, International Medical Corps

The Ministry of Health and Child Care (MOHCC), Zimbabwe for their support in prioritising adolescent girl nutrition and health in Zimbabwe.

The team of research assistants from the Amalima program

The Amalima program volunteers (Care Group Volunteers and Lead Mothers) whose dedication and hard work is second to none.

Disclaimer: The views and opinions of the author expressed herein do not necessarily state or reflect those of USAID or the United States Government.

Key words: adolescent, infant and young child feeding, Care Groups, nutrition, community 


\section{ABSTRACT}

The Amalima program in Matabeleland North and Matabeleland South Provinces of Zimbabwe, an intervention funded by the United States Agency for International Development (USAID) Office of Food for Peace, promoted Care Groups from 2014-2020. Care Groups are community peer- to- peer support groups that provide a platform for promoting optimal nutrition and health for pregnant and lactating women, as well as children 6-23 months of age through training sessions run by community group leaders to promote recommended maternal, infant and young child nutrition practices. A qualitative study was conducted to describe adolescent mother inclusion and participation in Care Groups, highlighting key enablers and barriers for participation. A total of 28 in-depth interviews were conducted with adolescents in Care Groups, as well as adolescents not participating in Care Groups. Focus group discussions were also held with family members of adolescents. The key enablers for Care Group participation by adolescent mothers were found to include the motivation to learn how to take care of their children, the social and interactive benefits, family support, and positive facilitator attitudes. Key barriers to participation were workload and chores at home, lack of family support, and lack of adolescent-friendly approaches amongst facilitators. Key recommendations include training facilitators on adolescentfriendly approaches and group dynamics so they can better understand and relate to adolescents. 


\section{INTRODUCTION}

Zimbabwe has a high national stunting prevalence rate of $26.2 \%$ (National Nutrition Survey, 2018) according to global standards (de Onis et al., 2019). Supporting nutrition in the first 1,000 days is known to improve foetal growth and birth outcomes, reduce stunting, improve economic prosperity, and, ultimately, save lives (Black, et al., 2008). The first 1000 days is the period from conception to a child's second birthday. This period has been identified as the most crucial window of opportunity for interventions to reduce stunting (Prentice et al., 2013).

It is evident that adolescents are often overlooked as a link to better nutrition in the first 1,000 days and yet prioritizing and engaging adolescents prior to and during the first 1,000 days can accelerate progress on improving nutrition and contribute to meeting multiple Sustainable Development Goals. Studies have shown that a high rate of teenage pregnancy contributes significantly to a high prevalence of malnutrition among under-five children (Finlay et al., 2011; Abrahams et al., 2011; Olodu et al., 2019). Given that the risk of child malnutrition increases with younger maternal ages, interventions should be targeted at teenage mothers and their children to reduce the risk of malnutrition. Research from the Young Lives study found that a child born to a stunted adolescent mother was associated with a 15 percent increased chance of the child being stunted, compared with a child born to a non-stunted older mother (Georgiadis et al., 2017). Furthermore, studies have shown that adolescent pregnancy is associated with child undernutrition through poorer maternal nutritional status, lower education, less health service access, poorer complementary feeding practices, and poorer living conditions (Nguyen et al., 2019). In addition, the nutritional needs of pregnant teenagers may compete with those of the developing foetus (Wemakor et al., 2018) because they are still growing. Teenage mothers may breastfeed for a shorter duration than older mothers (Sipsma et al., 2013), be behaviourally immature and therefore less sensitive to the needs of their infants, and may easily get annoyed and use less emotionally positive communication compared to adult mothers (Wemakor et al., 2018).

Adolescent pregnancy is a major public health problem, particularly in Africa (CondeAgudelo et al., 2005). Sub-Saharan Africa (SSA) has the world's highest level of adolescent pregnancy, estimated at 101 births per 1,000 women aged 15-19 years (Odimegwu \& Mkwananzi, 2016). In Zimbabwe, the adolescent fertility rate for women aged 15-19 years was 115 births per 1,000 women of the same age in 2015 (UNFPA, 2016). An assessment of adolescent girl nutrition and dietary practices and roles in Zimbabwe showed that adolescent girls had low levels of knowledge on nutrition, particularly nutrition during pregnancy (Reese-Masterton \& Murakwani, 2016). A case study conducted by International Medical Corps in Nigeria on adolescent inclusion in the Care Group approach concludes that the Care Group approach provides an opportunity to appropriately target adolescents to achieve improved maternal and child health and nutrition (Perera S, 2015).

\section{The Amalima program}

In the Matabeleland North and South provinces of Zimbabwe, the Amalima program, an intervention funded by the United States Agency for International Development (USAID) Office of Food for Peace, Care Groups were promoted from 2014 to 2020. The program was implemented by a consortium of organisations led by Cultivating New Frontiers in Agriculture and other partners included International Medical Corps, The Manoff Group, Organization of Rural Associations for Progress, Africare, and Dabane Water Workshops. The program worked with over 118,000 vulnerable households in the districts of 
Bulilima, Gwanda, Mangwe (Matabeleland South Province), and Tsholotsho (Matabeleland North Province).

International Medical Corps was responsible for implementing the Care Group approach, which has been endorsed by Zimbabwe's Ministry of Health and Child Care (MOHCC) as it

\section{Key Features of the Amalima Care Group Approach}

- The approach promotes optimal maternal and infant and young child nutrition in the first 1,000 days for prevention of chronic malnutrition

- Care Group sessions are participatory and led by trained community volunteers. Amalima had 425 Care Group Volunteers, and 1,713 Lead Mothers implementing Care Groups across the four districts

- The Care Groups leverage on the multiplier effect to reach large numbers of mothers and caregivers (up to 6,000 each month) with key messages each month

- Community Volunteers use context and culturally appropriate participatory materials in the local language - flipcharts and counselling cards

- A Care Group consists of up to 10 mothers or caregivers who meet once a month, to cover a session led by a trained Volunteer

- Care group sessions are held on a monthly basis

- The Community Volunteer (Lead Mother) conducts a follow up home visit to the mother/caregiver to offer one on one tailored support, and reach other family members with key messages

- Mothers/caregivers participate in the Care Group from pregnancy until the child is 2 years of age is an impactful innovative, low-cost community-based strategy that promotes optimal maternal and infant and young child nutrition (MIYCN). Care groups are peer-topeer support groups of about 10 mothers (pregnant or lactating women and caregivers of young children) that meet on a regular basis. The Care Group approach has the advantage of reaching a large number of caregivers using trained community health workers or volunteers. Within the Amalima Care Group approach, Supervisors/Nutrition Officers (NOs) who are paid program staff met with, taught and supported

Promoters/Field Officers (FOs) who were also paid program staff. They in turn met with, taught, and supported Care Group Volunteers (Ministry of Health Village Health Workers).

Monthly, each FO was responsible

for training and supportive supervision to a group of 5 to 12 Care Group Volunteers (CGVs). The CGVs mentored and supported Lead Mothers (LM), who are a lower-level cadre of community volunteers to work with groups of up to 10 mothers and caregivers (who are referred to as the Care Group). The group sessions with mothers and caregivers are led by a facilitator (Lead Mother), with the objective of imparting knowledge, practices and skills for the adoption of nutrition, health and hygiene behaviours. Figure 1 presents the structure of the Amalima Care Group model.

Through the multiplier effect of Care Groups, one CGV can potentially support 10 LMs who can go on to support upto 100 Care Group members and their families. From program onset, extrinsic motivation was critical to motivate the Care Group Volunteers in carrying out the program activities. The program used job-aide related incentives (bicycles to facilitate mobility, t-shirts with messages, bags to carry training materials) to motivate the Care Group Volunteers and LMs. Care Group participants received a recipe book to encourage them to prepare nutritious meals taught during the community cooking sessions.

Whilst extrinsic incentivisation has been critical in motivating the Care Group Volunteers, intrinsic motivation has played a key role for sustained motivation of the volunteers. Through Care Groups, LMs reach mothers and caregivers each month with tailored messages 
promoting the adoption of recommended maternal, infant and young child nutrition behaviours, the key behaviours are presented in Table 1 .

Amalima Care Group model - district structure

$\begin{array}{ll}\text { Nutrition } & \text { NO supervises } \\ \text { Officer (NO) } & 9 \text { Field Officers (FO) }\end{array}$

穴

$\uparrow$

$\dot{A}$

MOHCC

District

Nutritionist
FO supervises upto 12 CGVs

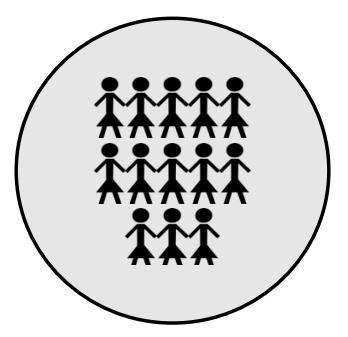

LM supports CG members

CGV supervises upto $10 \mathrm{LMs}$

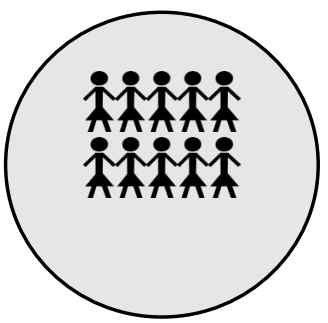

10

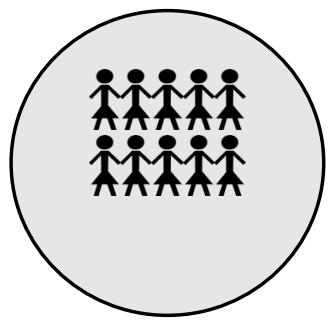

Figure 1. Amalima program Care Group model (Ncube-Murakwani, 2020)

In the Amalima program areas, about $20 \%$ of mothers are adolescents. The need for tailored services for pregnant adolescent girls throughout pregnancy and beyond would help ensure good nutritional practices and status during the critical '1,000-day window of opportunity'. Adolescent mothers are encouraged to participate in Care Groups with the specific aim to ensure improved nutrition outcomes for themselves and their children;

The program introduced sport and cooking competitions as interesting activities to attract the participation of younger women. Despite such innovative activities, the participation of adolescent mothers in Care Groups remained low. An earlier article in the journal World Nutrition summarized the critical factors for success in general from the Amalima program in rural Zimbabwe (Ncube-Murakwani et al., 2020). The research reported here explores the enablers and barriers specifically for adolescent mother participation in Care Groups.

Findings and recommendations from this study will help inform future strategies for effective engagement of adolescents in Care Groups and other global programs engaging adolescent mothers.

\section{Methods}

This study included in-depth interviews with adolescent mothers aged between 16 to 19 and employed qualitative research methods including focus group discussions (FGD) and key informant interviews (KIIs). Boddy (2016) highlights that in qualitative research, the determination of sample size is contextual and partially dependent upon the scientific paradigm under which investigation is taking place. For example, qualitative research which is oriented towards positivism, will require larger samples than in-depth qualitative research 
does, so that a representative picture of the whole population under review can be gained. On the other hand, samples of only 12 may be adequate where data saturation occurs among a relatively homogeneous population. For this study, the population of adolescent mothers was found to be relatively homogenous, and data saturation was reached with a sample size of 28 .

Table 1. Infant and young child feeding behaviours promoted through the Care Groups

\begin{tabular}{|c|c|c|}
\hline & Infants Under 6 months & \\
\hline & $\begin{array}{l}\text { Daytime breastfeeds are increased to at } \\
\text { least } 8 \text { feeds during the day, and } 4 \text { feeds at } \\
\text { night (up to } 12 \text { feeds in 24hours) } \\
\text { Mothers practice good attachment and } \\
\text { positioning }\end{array}$ & $\begin{array}{l}\text { - Mothers empty one breast completely and offer the } \\
\text { other at each feeding } \\
\text { - Mothers avoid giving water and complementary } \\
\text { foods before } 6 \text { months }\end{array}$ \\
\hline & Babies 6 -11 months & \\
\hline & $\begin{array}{l}\text { Mothers increase number of meals up to } 3 \\
\text { times per day } \\
\text { Mothers/care givers enrich porridge with } \\
\text { nuts, legumes and vegetables }\end{array}$ & $\begin{array}{l}\text { - Mothers/caregivers feed animal source foods at } \\
\text { least } 2 \text { times each week } \\
\text { - Mothers/ caregivers give } 1 \text { nutrition snack per day } \\
\text { from available food }\end{array}$ \\
\hline & Young Children 12-23 months & \\
\hline \multicolumn{2}{|r|}{$\begin{array}{l}\text { Recommendations for 6-11 months plus... } \\
\text { - } \quad \text { Give } 2 \text { nutritious snacks per day from } \\
\text { available food }\end{array}$} & $\begin{array}{ll}\text { - } & \text { Feed child from a separate bowl } \\
\text { - } & \text { Avoid sweets, tea and junk foods }\end{array}$ \\
\hline \multicolumn{3}{|c|}{ All Sick Infants and Young Children } \\
\hline & $\begin{array}{l}\text { During and after illness } \\
\text { mothers/caregivers increase number of } \\
\text { daily meals }\end{array}$ & $\begin{array}{l}\text { - Mothers/caregivers feed small frequent meals (for } \\
\text { at least } 2 \text { weeks while recovering) }\end{array}$ \\
\hline & Pregnant and Lactating women & \\
\hline & $\begin{array}{l}\text { Pregnant women attend at least } 4 \\
\text { Antenatal Care visits during pregnancy, } \\
\text { the first one being in the first trimester } \\
\text { Pregnant women take Iron/folate tablets as } \\
\text { directed by Health facility staff everyday } \\
\text { throughout pregnancy }\end{array}$ & $\begin{array}{l}\text { - Pregnant women eat one extra meal a day of } \\
\text { diverse foods } \\
\text { - Lactating mothers eat } 2 \text { extra meals a day of } \\
\text { diverse foods }\end{array}$ \\
\hline
\end{tabular}

Source: Amalima program (2014-2020) documents

This research was conducted in two districts (Gwanda district in Matabeleland South Province and Tsholotsho district in Matabeleland North Province) across four villages purposively selected because they had high numbers of adolescent mothers. Adolescent mothers participating in Care Groups, participated in mixed Care Groups (with older women) as the program did not promote adolescent only Care Groups. To ensure that the study captured varied responses based on participant experiences, not more than two participants were interviewed from the same Care Group. The author and research assistants purposively sampled from following groups:

1) Adolescent mothers of children 0-23 months attending at least four Care Group lessons in the last 6 months

2) Adolescent mothers of children 0-23 months never having attended a Care Group lesson

3) Relatives of adolescent mothers who did and did not participate in Care Groups

4) Care Group Volunteers and Lead Mothers 
The research aimed to reach about $80 \%$ level of saturation, which has been shown to be achieved through two to three focus groups among participants with the same characteristics (Guest et al., 2016). A total of 11 focus group discussions were conducted. (See Table 2 for details.)

Table 2. Study sample

\begin{tabular}{|c|c|c|c|c|c|}
\hline & $\begin{array}{l}\text { Gwanda } \\
\text { district }\end{array}$ & $\begin{array}{l}\text { Tsholotsho } \\
\text { district }\end{array}$ & Total & Participants & Participant Details \\
\hline $\begin{array}{l}\text { In depth } \\
\text { interviews }\end{array}$ & 11 & 10 & 21 & $\begin{array}{l}\text { Adolescent mothers } \\
\text { participating in Care } \\
\text { Groups }\end{array}$ & $\begin{array}{l}\text { Youngest } 16 \text { years old. } \\
\text { Eldest } 19 \text { years old } \\
\text { Median age: } 18 \text { years } \\
3 / 21 \text { married }(16.6 \%) \text {. } \\
20 / 21(95.2 \%) \text { have } \\
\text { one child. }\end{array}$ \\
\hline $\begin{array}{l}\text { In depth } \\
\text { interviews }\end{array}$ & 5 & 2 & 7 & $\begin{array}{l}\text { Adolescent mothers } \\
\text { not participating in } \\
\text { Care Groups }\end{array}$ & $\begin{array}{l}\text { Youngest } 16 \text { years old. } \\
\text { Eldest } 19 \text { years old } \\
\text { Median age: } 18 \text { years } \\
2 / 7 \text { married }(40 \%) \text {. All } \\
\text { have one child. }\end{array}$ \\
\hline $\begin{array}{l}\text { Focus group } \\
\text { discussions }\end{array}$ & 4 & 1 & 5 & $\begin{array}{l}\text { Family members of } \\
\text { adolescents } \\
\text { participating in Care } \\
\text { Groups }\end{array}$ & $\begin{array}{l}\text { Mostly female family } \\
\text { members (mothers, } \\
\text { mothers in law, aunts, } \\
\text { grandmothers); } 1 \text { male } \\
\text { family member }\end{array}$ \\
\hline $\begin{array}{l}\text { Focus group } \\
\text { discussions }\end{array}$ & 2 & 3 & 3 & $\begin{array}{l}\text { Family members of } \\
\text { adolescents not } \\
\text { participating in Care } \\
\text { Groups }\end{array}$ & $\begin{array}{l}\text { All female family } \\
\text { members (mothers, } \\
\text { mothers in laws, aunts) }\end{array}$ \\
\hline $\begin{array}{l}\text { Focus group } \\
\text { discussions }\end{array}$ & 1 & 2 & 3 & $\begin{array}{l}\text { Care Group } \\
\text { Volunteers and Lead } \\
\text { Mothers }\end{array}$ & $\begin{array}{l}6 \text { CGVs; } 17 \text { Lead } \\
\text { Mothers (all female) }\end{array}$ \\
\hline
\end{tabular}

Semi-structured interview guides were developed separately for the in-depth interviews (IDI) and focus group discussions (FGD), in accordance with standardised guidance on qualitative research (Busetto et al., 2020). Prior to data collection, the author and research assistants underwent a 3-day training on FGD and key informant interview (KII) methodology, including facilitation techniques, note-taking methods, consent acquisition, and ethics of conducting interviews with adolescents. Tools were pre-tested by the research team with adolescent mothers, family members and project volunteers in Gwanda district.

\section{Data collection}

The data were collected by a team of research assistants (Amalima staff) who have previously conducted similar assessments within the Amalima program areas. Data collection was conducted over a period of 5 days in November 2019. During each data collection session, there was a moderator and a dedicated notetaker. Interviews were also recorded and then translated and transcribed from the Ndebele language directly into English for data analysis and reporting. Transcripts were compared with detailed notes taken by the notetaker to verify their accuracy and clarify any instances where the transcriber was not able to identify the speaker. The moderator and notetaker reviewed the transcripts together. IDIs were conducted 
indoors and lasted approximately 30 minutes; FGD were conducted outdoors and lasted between 60 minutes to 90 minutes.

\section{Data analysis}

Transcribed data was entered in Excel and analysed inductively where the author and research assistants analysed the transcripts and developed a list of codes based on emerging themes. These codes were then grouped into major themes where all transcripts were coded by two researchers. The researchers employed constant comparison and triangulation to ensure that all codes and themes were grounded in the data. In addition, during the coding and analysis process, the researchers engaged in analytical dialogue, which enhanced the study's rigor and minimized individual researcher bias. Any inconsistencies were discussed and resolved. After the completion of coding, data were compiled, manually analysed and interpreted and the key themes and key illustrative quotes highlighted.

\section{Ethical considerations}

Prior to data collection, the Amalima program Technical Learning Unit team reviewed the protocol and data collection tools. To protect confidentiality, all discussions were held in a private space, and no names were included in transcripts. Verbal informed consent was obtained from all participants and participants were informed that they could withdraw from the research at any time without penalty. Only members of the research team had access to the recordings and transcripts.

\section{Results}

\section{Enablers of participation}

\section{Motivation to learn childcare techniques}

Most adolescent Care Group mothers highlighted that they participate in Care Groups because they are motivated by the knowledge they get specifically on taking good care of

\begin{tabular}{l} 
WHAT MOTIVATES ADOLESCENT \\
MOTHERS TO PARTICIPATE IN CARE \\
GROUPS? \\
- Motivation to learn how to take care of \\
their children and have a hygienic home \\
- Social and interactive benefits through \\
fun and exciting sessions such as the \\
cooking demonstrations and learning \\
from other mothers \\
- Benefitting from the program's \\
- supplementary food rations \\
- Family support \\
Facilitator attitude, perception and skills \\
\hline
\end{tabular}
their children. Importantly, one of the mothers stated that 'I learn for my child. I learned that my child must eat 5 times as my baby is over 6 months old, and I practised that and my child is growing well'. They pointed out that they found the Amalima program pictorial flipcharts informative and interesting. A common sentiment from the mothers was that they had a sense of pride in having healthy, strong children, citing that from the Care Groups they had learned about preparing nutritious foods for their children and that enriching the baby's porridge with locally available ingredients had given them valuable knowledge. A mother explained 'I learned how to enrich my baby's porridge with eggs, kapenta (small dried fish) and mopane worms'.

It was notable that all of the mothers expressed that the Care Group sessions were appropriate for them, as they learnt about breastfeeding and child feeding which were important for them. Interestingly, the learning had been internalised, as mothers were able to give specifics such as 'If the child is 6 months old, you start by giving him or her 3 spoons of porridge. It's important to enrich the porridge, and you can add egg to the porridge to make it more 
nutritious'. Most mothers indicated that two-hour Care Group sessions were common and preferable to longer ones.

\section{Social and interactive components}

Most Care Group participants indicated that they valued interacting with other mothers whilst learning about taking care of their babies. This was both fun and important for them, given that all of them were first time mothers. Most, Care Group participants had participated in interactive cooking demonstrations where they had learned how to prepare a variety of nutritious foods appropriate for child feeding. More than half of the mothers had recipe books from the program and they cited that having a recipe book motivated them to participate in the Care Group sessions and to try out different recipes at home. Some of the mothers mentioned that they found the sporting activities, dramas or role-plays, singing and dancing fun, as this gave them a chance to engage with other mothers. The CGVs and LMs all agreed that sporting activities, drama and role-play and cooking demonstrations have had a big role in motivating adolescent mother participation in the Care Groups. The researchers think that the Care Group had become a social learning hub for the mothers to engage in fun, interactive ways whilst learning about child nutrition and care practices.

The adolescent non-Care Group members mostly recommended that such interactive activities make Care Groups more appealing, but that there should be a competition element with prizes to incentivise the winners.

\section{Ration provision}

The Amalima program was distributing supplementary non-conditional food rations for pregnant and lactating mothers as part of the program's stunting reduction efforts. Some of the CGVs and LMs highlighted that adolescent mothers are mostly motivated by receiving the rations, Care Group participation was not a requirement to receive food rations. The discussants also highlighted that very young mothers value the rations more than the Care Group learning, as they do not understand the value of the Care Group lessons. This sentiment was emphasised by an LM who stated 'Some have babies at a very young age, even from as young as 14 or 15, and it is hard for them to understand the need for Care Group lessons. For these young mothers, they place importance on the rations, and do not appreciate the benefits of the knowledge they could gain from the lessons'.

\section{Family support}

Most first-time adolescent mothers in the program areas live in multi-generational, extended family households. It is notable that a supportive family environment was a key enabler for adolescent mother participation in the Care Groups. Family members of adolescent mothers participating in Care Groups all agreed that adolescent mothers learned a lot about child care and better hygiene practices from the Care Groups, and that it was very important for the young mothers to participate in the sessions. The family members indicated that they were supportive of adolescent mother participation in Care Groups, with one family member explaining, 'Care Groups teach the young mothers about exclusive breastfeeding. Even I now know the baby should have nothing other than the mother's milk for the first 6 months'. On being asked whether adolescent mothers participating in Care Groups ever share information with their family members on what they learn, most of the focus group participants indicated that the mothers do share information. One family member stated that 'It's important that they share the information with us. They leave their children with us sometimes, so we need to know how to take care of them when they [the mothers] are away'. One married adolescent 
mother said, 'My mother-in-law is happy because I have brought good changes into the home. I keep my in-laws homestead clean, as I have gained lots of knowledge from my Care Group. A clean home gives my mother-in-law a sense of pride'. All except one of the mothers indicated that no one disapproved of their participation in the Care Group activities.

\section{Facilitator attitude, perception and opinion}

Almost all the adolescent mothers spoke positively about the LM. Of key note they expressed sentiments such as the LMs is 'kind and patient'. Other key sentiments were that the Lead Mother helped group members to interact, by engaging everyone in the discussions that took place during the Care Group sessions. Some of the adolescents described their LMs as 'kindhearted', and not short tempered. One of the adolescent mothers stated 'She (the Lead Mother) is easy to talk to', and another stated 'if you do not understand something, she (the Lead Mother) explains repeatedly until you do'. Interestingly, some of the adolescent mothers pointed out the importance of the LMs showing genuine interest for their welfare and wellbeing. This was obviously important for the mothers, and one of the adolescent mothers stated 'my Lead Mother teaches well and encourages us to engage in Village, Savings and Lending activities so that we were able to buy nutritious foods for our little ones'. The attitude of the Lead Mother was therefore recognised as a key enabler for adolescent mother participation in the Care Groups.

On being asked about the differences in the health and nutritional statuses of children of adolescent mothers in Care Groups and those not in Care Groups, the CGVs and LMs all agreed that there was a notable difference. The discussants stated that 'Care Group members have healthy babies compared to non-Care Group members.' In addition, they cited that there was a stark difference in child feeding practices between them. One LM stated 'Care Group members give nutritious snacks to their babies like the peanut dumplings they have learned to make at the cooking sessions, while non-Care Group members usually give nonnutritious corn snacks like Jiggies' (salty corn-snacks).

\section{Barriers to participation}

\section{Workload}

Most of the adolescent non-Care Group mothers indicated that they had heard about Care Groups, mostly through the supplementary food ration distribution sessions. The adolescent mothers had a good perception about the Care Groups, recognising them as groups where

REASONS FOR NON-PARTICIPATION OF ADOLESCENT MOTHERS IN CARE GROUPS

- Workload and chores at home

- Peer cliques which often leave other adolescents feeling excluded

- Lack of family support: Adolescents need permission to participate in Care Groups, this is not always granted

- Facilitator perception, attitude and skills: Lead Mothers lack capacity and skills on adolescent friendly approaches

- Adolescents are only motivated by porridge (supplementary food rations) and not so much the 'learning'

- Some adolescents as young as 14 or 15 do not understand the importance of Care Groups information on aspects such as good hygiene, breast-feeding and baby feeding was shared. On being asked why they were not participating in Care Groups, some of the adolescent mothers cited an issue of workload and chores at home. One adolescent mother stated 'I am interested in the Care Groups, but household chores prevent me from participating. My mother-in-law says the household chores are important'. From the focus group discussion with family members of adolescent non-Care Group family members, one of the participants explained 'They (adolescent mothers) are free to attend lessons as long as they do their chores on time. There is an issue of laziness as some 
of them are lazy and don't do their chores on time'. Most of the family members of adolescent non-Care Group mothers described adolescent mothers as lazy, disrespectful and stubborn, naming these as the common behavioural traits amongst this group, which contributed to their non-participation in Care Groups. One of the parents explained 'Children of nowadays lack respect. They do not listen to their elders; they tell us what to do, yet we are the parents'. It was notable that a few of the mothers indicated that the sessions lasted three to four hours, which was long for them as they had other chores, which they needed to also prioritise.

\section{Social exclusion ("peer cliques")}

A key barrier highlighted by the adolescent mothers was that Care Group attendees pick and select each other, leaving adolescent non-Care Group attendees feeling left out. This happens from the natural formation of peer cliques that happens in the community, especially amongst adolescents. This social exclusion happens despite the fact that the adolescent mothers are invited systematically into the Care Groups and provided with the same information as older mothers. One adolescent mother cited 'People pick and choose who they meet with; it's the same in these groups. There is segregation and discrimination within the community'. The adolescent non-Care Group members mostly recommended that there should not be a culture of 'selection' or peer cliques when it comes to Care Groups, and that the onus was on the LM to discourage this type of culture.

\section{Lack of family support}

Notably, over half of the adolescent mothers stated that they need permission to take part in Care Group activities. However, all except one of the mothers indicated that no one disapproved of their participation in the Care Group activities. From the focus group with family members of adolescent mothers in Care Groups, all participants agreed that adolescent mothers need permission from the family members that they live with. A family member stated 'Eighteen- and nineteen-year-olds are young and they still live with their families. As parents, we see them as children. They need to get permission to attend Care Group sessions'.

\section{Facilitator perception, attitude and opinion}

The attitude of the LM is a theme that comes up a few times mostly as an enabler but it could also be a barrier to Care Group participation. Almost all the LMs described adolescent mothers as being lazy and arrogant. One of the LMs explained 'Older women attend Care Groups more than adolescent mothers do. Adolescent mothers are lazy and they always need follow-ups, whereas some are just arrogant'. From the researcher's perspective, the attitudes of LMs and CGVs towards adolescent girls could be a hindrance to adolescent mother participation in Care Groups. Adolescent mothers have unique developmental needs and different barriers compared to adult women, and the LMs may not be adequately equipped to deal with these.

\section{Shyness}

Whilst half of the adolescent mothers stated that they are able to freely express themselves during the Care Group sessions, the other half were shy and unable to freely express themselves. One adolescent mother stated, "I feel free to share experiences...but I have never really shared anything'. Another pointed out 'we cannot really express ourselves. We express ourselves freely to a lesser extent... we are scared of being told off or reprimanded'. On 
sharing her experiences, she went on to say, 'It is hard to come forward and share your story as a young mother because others might laugh at us'. Most of the CGVs and LMs stated that shyness was a key reason for adolescent mothers' non-participation in Care Groups, as one $\mathrm{CGV}$ stated 'Older women are more responsive compared to the younger ones who are too shy to attend learning sessions'.

\section{Dynamics of mixed age groups}

Most of the adolescent mothers stated that they preferred mixed Care Groups where adolescent mothers took part in Care Group sessions together with older mothers. The main reasons cited were that the adolescent mothers were able to learn from the experiences of the older, more mature mothers. One adolescent mother cited 'it's better to have the older mothers in Care Groups. In our culture we say 'good guidance comes from those who have gone before you'. Upon further probing, some of the mothers highlighted that within an adolescent only Care Group they would find it easier to express themselves; but given the option of mixed or adolescent Care Groups - the mixed Care Group was most preferred. Interestingly, CGVs and LMs stated that adolescent mothers needed to have their own Care Group so that they are free to express themselves during the Care Group sessions.

\section{Discussion}

Care Groups provided adolescent mothers with key knowledge on maternal, infant and young child nutrition practices and it was notable that they were adopting the recommended practices. This is similar to findings from a case study on adolescent participation in Care Groups that was conducted in Nigeria (Perera, 2015). A top motivating factor for adolescent participation in Care Groups was summarized in the statement 'I learn for my child', and many of the adolescent mothers echoed this. It is therefore interesting that, according to what they said to the researchers, this was the best incentive for participating in the Care Groups.

Adolescent mothers not participating in Care Groups were faced with various barriers that include workload and chores. Tinago et al. (2020) found that adolescent mothers need strong adult community support and health knowledge to address important social issues that impact their health and well-being and that facilitated peer support groups can strengthen social networks and mitigate the adverse effects of social isolation and stigma among these mothers. Psychosocial factors played a key role as determinants for Care Group participation as evidenced by the existence of peer cliques, which resulted in some of the adolescents feeling left out or excluded. Adolescent peer cliques have

\section{Key Message} enablers to adolescent mother participation in community nutrition support groups. To encourage adolescent mother participation in support groups, a tailored approach that meets the unique needs of this target population is necessary
The study outlines the key barriers and been identified as a developmentally important unit of analysis as they form a setting in which adolescents hang around, gain a sense of belonging and receive support (Pattiselanno et al, 2015). EllisSloan (2015) argues that group-based programmes convey particular advantages in providing such support for young parents. These include peer learning, the development of friendships as a form of social support, and respite.

CGVs and LMs described the adolescent non-Care Group mothers as shy, arrogant, lazy and needing a lot of follow-up. Ngum Chi Watts et al. (2015) found that teenage mothers reported that they were frowned upon by their wider communities, which left them with feelings of shame and embarrassment. Adolescents have 
unique developmental needs and different barriers compared to adult women, and the CGVs and LMs may not be equipped to adequately support them. This suggests that there is a 'disconnect' in terms of their understanding of adolescent behaviours and reiterates the need for bridging that disconnect. These findings strongly corroborate with the fact that the CGVs and LMs need to be capacitated on adolescent friendly approaches and group dynamics. Geary et al. (2014) highlighted the need for youth-friendly services and approaches in terms of staff attitudes and actions. They argue that training and on-going support should be provided to facilitate this.

Both the adolescent Care Group participants and non-Care Group participants highlighted the importance of having interactive activities such as sport and community cooking sessions to motivate them to participate. Although, most of the Care Group activities had promoted sports and cooking sessions, these sessions had not been held in recent months; therefore, some of the participants had never taken part in the activities.

The study found that for both adolescent Care Group, and non-Care Group participants, the need for permission to attend or participate in Care Groups was important as adolescent mothers are seen as children. Permission was therefore integral; however, refusal to provide permission was not mentioned as a barrier. This suggests that adolescent family members need to be made aware of the Care Group activities from the on-set, as was noted with family members of adolescent Care Group participants who were all convinced that there was great benefit for adolescent mother participation in Care Group activities.

The CGV and LM perspective favoured the formation of adolescent only Care Groups over mixed Care Groups, citing that the adolescents would be free to express themselves and overcome any shyness in groups with only their peers. However, replacing mixed Care Groups with adolescent only Care Groups needs to be looked at carefully before any decision is made, as the adolescent mothers seem to place a lot of value in learning from older more experienced mothers.

\section{Limitations}

- The program staff (the author and research assistants) who implemented the research were actively engaged in the Amalima program's implementation of the Care Group approaches, and may not have been strictly impartial. However, strong efforts have been made to minimize resultant bias, by using external reviewers throughout the research process.

- During the process of translation from Ndebele to English, there may have been some loss of information, however this is expected to be minor and will have minimal impact on overall quality of data.

- We cannot rule out the possibility that some of our findings were due to response bias, with adolescents especially tending to report what they thought would make them look good or what they thought the researchers wanted to hear.

\section{Conclusions}

This study contributes to the search for best practices in promoting adolescent participation in Care Groups. The lessons learned and recommendations from the qualitative study can be used to advocate for greater adolescent inclusion in Care Group activities and other programs, 
as well as giving specific insight on the necessary adaptations that can be made to meet the unique needs of this target population.

Other areas for future programming include exploring a model for adolescent only Care Groups. Another area for future research is the extent to which Care Groups can be modified and adapted within the high school setting.

\section{Recommendations}

As informed by the study findings, we recommend the following:

1. Build the capacity of CGVs and LMs on adolescent friendly approaches so they can better understand and relate to adolescents. The curriculum for training CGVs and LMs should include this component.

2. Train LMs on key aspects of group dynamics, to better manage the issues of peer cliques, and promote a culture that encourages social cohesion and psychological safety (by creating a context where individuals feel psychologically safe to engage, learn, and develop) within the Care Group. This will create an environment where Care Group members can feel freer to express themselves, including the shy members within the group.

3. LMs could prioritize conducting home visits to adolescent mother homes, taking the opportunity to reach and engage with adolescents' family members, and help them understand the importance of adolescent participation in Care Groups.

4. Scale up the use of fun and engaging activities such as sporting activities (netball), edutainment, and community cooking sessions - this was a key recommendation from most of the adolescents as well as the CGVs and LMs.

5. The timing and length of Care Group sessions needs to accommodate the fact that adolescent mothers need to dedicate time to do other chores.

6. Within the Care Group, pilot different models for adolescent participation such as:

- Mixed group (with adolescent mothers and older mothers) with a mentorship component where adolescent mothers are paired up with an older, experienced mother in the Care Group. This can encourage a mentor-mentee relationship, which contributes to the adolescents feeling that they are part of the group, and ultimately greater social cohesion.

- Adolescent only Care Groups

- Mostly adolescent only Care Groups with just a few older women for a mentorship component

7. Improve community awareness about the Care Group, encouraging an enabling environment at home that would help non-participating adolescents to join

8. Share findings from this study with the Ministry of Health and Child Care to consider how best to integrate adolescent-friendly approaches into the National Care Group strategy for Zimbabwe. 


\section{References}

Abrahams Z, McHiza Z, Steyn NP. 2011. Diet and mortality rates in Sub-Saharan Africa: stages in the nutrition transition. BMC Public Health. 11:801. doi:10.1186/1471-2458-11-801

Black RE, Allen LH, Bhutta ZA, et al. 2008. Maternal and child undernutrition: global and regional exposures and health consequences. Lancet. 371 (9608):243-260. doi: $10.1016 / \mathrm{S} 0140-6736(07) 61690-0$

Boddy CR. 2016. Sample size for qualitative research. Qualitative Market Research: An International Journal. 19(4):426-432. https://doi.org/10.1108/QMR-06-2016-0053

Busetto L, Wick W, Gumbinger C. 2020. How to use and assess qualitative research methods. Neurol Res Pract. 2:14. https://doi.org/10.1186/s42466-020-00059-Z

Conde-Agudelo A, Belizán JM, Lammers C. 2005. Maternal-perinatal morbidity and mortality associated with adolescent pregnancy in Latin America: cross-sectional study. Am J Obstet Gynecol. 192(2):342-9.

de Onis M, Borghi E, Arimond M, Webb P, Croft T, Saha K, et al. 2019. Prevalence thresholds for wasting, overweight and stunting in children under 5 years. Public Health Nutrition. 22(1):175-179. doi: 10.1017/S1368980018002434.

Ellis-Sloan, K. 2015. Practising care in teenage mother support groups. Critical Social Policy. 35:535 - 555.

Finlay JE, Özaltin E, Canning D. 2011. The association of maternal age with infant mortality, child anthropometric failure, diarrhoea and anaemia for first births: evidence from 55 lowand middle-income countries. BMJ Open. 1(2):e000226. doi: 10.1136/bmjopen-2011-000226

Food and Nutrition Council of Zimbabwe. 2018. Zimbabwe National Nutrition Survey 2018. http://fnc.org.zw/wp-content/uploads/2019/01/Zimbabwe-2018-National-Nutrition-Survey$\underline{\text { Report.pdf }}$

Geary RS, Gómez-Olivé FX, Kahn K, Tollman S, Norris SA. 2014. Barriers to and facilitators of the provision of a youth-friendly health services programme in rural South Africa. BMC Health Serv Res. 14:259. https://doi.org/10.1186/1472-6963-14-259

Georgiadis A, Penny ME. 2017. Child Undernutrition: Opportunities beyond the First 1000 Days. The Lancet Public Health, 2(9):e399, doi: 10.1016/s2468-2667(17)30154-8.

Guest G, Namey E, McKenna K. 2016. How many focus groups are enough? Building an evidence base for nonprobability sample sizes. Field Methods. 29(1):3-22.

Ncube-Murakwani P, Moyo S, Nyathi C, Dzimba M, Maphosa M, Dube SB. 2020. Implementing Care Groups for improved maternal and child nutrition: Critical factors for success from the Amalima program in rural Zimbabwe. World Nutrition. 11(2):90-107. https://doi.org/10.26596/wn.202011290-107 
Ngum Chi Watts MC, Liamputtong P, McMichael C. 2015. Early motherhood: a qualitative study exploring the experiences of African Australian teenage mothers in greater Melbourne, Australia. BMC Public Health 15, 873. https://doi.org/10.1186/s12889-015-2215-2

Nguyen PH, Scott S, Neupane S, Tran LM, Menon P. 2019. Social, biological, and programmatic factors link adolescent pregnancy to early childhood undernutrition: a path analysis of India's 2016 National Family and Health Survey. Lancet Child Adolesc Health. 3(7):463-73. http://dx.doi.org/10.1016/S2352-4642(19)30110-5

Odimegwu C, Mkwananzi S. 2016. Factors Associated with Teen Pregnancy in sub-Saharan Africa: A Multi-Country Cross-Sectional Study. Afr J Reprod Health. 20(3):94-107. doi: 10.29063/ajrh2016/v20i3.14.

Olodu MD, Adeyemi AG, Olowookere SA, et al. 2019. Nutritional status of under-five children born to teenage mothers in an urban setting, south-western Nigeria. BMC Res Notes. 12:116. https://doi.org/10.1186/s13104-019-4147-X

Pattiselanno K, Dijkstra JK, Steglich C, et al. 2015. Structure Matters: The Role of Clique Hierarchy in the Relationship Between Adolescent Social Status and Aggression and Prosociality. J Youth Adolescence. 44:2257-2274. https://doi.org/10.1007/s10964-015-0310$\underline{4}$

Perera SM. 2015. Case Study on Adolescent Inclusion in the Care Group Approach - the Nigeria Experience. Field Exchange. 52:110. https://www.ennonline.net//fex/52/adolescecaregroup

Prentice AM, Ward KA, Goldberg GR, et al. 2013. Critical windows for nutritional interventions against stunting. Am J Clin Nutr. 97(5):911-918. doi: 10.3945/ajcn.112.052332

Reese-Masterson A, Murakwani P. 2016. Assessment of adolescent girl nutrition, dietary practices and roles in Zimbabwe. Field Exchange. 52:113.

https://www.ennonline.net/fex/52/adolescentgirlnutrition

Sipsma HL, Magriples U, Divney A, Gordon D, Gabzdyl E, Kershaw T. 2013. Breastfeeding behavior among adolescents: initiation, duration, and exclusivity. $J$ Adolesc Health.

53(3):394-400. doi: 10.1016/j.jadohealth.2013.04.005

Tinago C, Frongillo E, Warren A, Chitiyo V, Cifarelli A, Fyalkowski S, Pauline V. 2020. Community-Based Peer Support Intervention to Mitigate Social Isolation and Stigma of Adolescent Motherhood in Harare, Zimbabwe. Pilot and Feasibility Studies Preprint. 10.21203/rs.3.rs-48978/v1.

UNFPA. 2016. National Adolescent Fertility study report. https://zimbabwe.unfpa.org/sites/default/files/pubpdf/UNFPA $\% 20$ NAFS $\% 20$ Main $\% 20$ Report $\% 20 \% 202016 \% 20$ For $\% 20$ Web.pdf

Wemakor A, Garti H, Azongo T, Garti H, Atosona A. 2018. Young maternal age is a risk factor for child undernutrition in Tamale Metropolis, Ghana. BMC Res Notes. 11(1):877. doi: 10.1186/s13104-018-3980-7 